\title{
Optimal Algorithms for Voltage Management in Distribution Systems Interconnected with New Dispersed Sources
}

\author{
Dae Seok Rho ${ }^{\dagger}$, Kyung Soo Kook* and Yong Peel Wang**
}

\begin{abstract}
The optimal evaluation algorithms for voltage regulation in the case where new dispersed sources are operated in distribution systems are studied. Handling the interconnection issues for proper voltage managements are often difficult and complicated because professional skills and enormous amounts of data during evaluations are needed. Typical evaluation algorithms mainly depend on human ability and quality of data acquired, which inevitably cause the different results for the same issue. Thus, unfair and subjective evaluations are unavoidable. In order to overcome these problems, we propose reasonable and general algorithms based on the standard model system and proper criterion, which offers fair and objective evaluation in any case. The proposed algorithms are divided into two main themes. One is an optimal algorithm for the voltage control of multiple voltage regulators in order to deliver suitable voltage to as many customers as possible, and the other is a proper evaluation algorithm for the voltage management at normal and emergency conditions. Results from a case study show that proposed methods can be a practical tool for the voltage management in distribution systems including dispersed sources.
\end{abstract}

Keywords: Voltage management, New dispersed sources(NDS), Interconnection, Voltage regulator

\section{Introduction}

Recently, new dispersed sources (NDS) such as photovoltaic, solar, fuel cell, energy storage, etc. are energetically interconnected and operated in distribution systems as one countermeasure of the national projects for alternative energy strategy with the provision against oil crisis. In some countries, the technical guidelines on the interconnection of NDS have been established and conducted positively and some special laws have also been enacted to promote the introduction of NDS. However, adapt them to the operation of distribution systems is not easy because the guidelines and their references require the professional skills and knowledge ${ }^{[1]-[2]}$. Under these circumstances, this paper presents more convenient and effective algorithms for voltage managements of NDS. The proposed algorithms are designed for the purpose of fair and objective evaluation based on the standard model systems and proper criterions as compared with the typical algorithms, which depending on the individual ability of person in charge and the quality of data acquired for simulations ${ }^{[3]-[7]}$. As the algorithm can offer reasonable evaluation and some countermeasures in advance, the planners and manufactures can prevent several problems related to interconnection of NDS. Their economical profit can be also expected by avoiding the additional options such as compensation of reactive

\footnotetext{
$\dagger \quad$ Corresponding Author: Dept. of Electrical Engineering, Korea University of Technology, Korea.(dsrho@kut.ac.kr)

* Dept. of Electrical Engineering, Chonbuk National University, Korea.(kskook@jbnu.ac.kr)

** Electrical Industry Researcher Institute of Korea, Korea.(ypwang@erik.re.kr)
}

Received: October 28, 2010; Accepted: November 24, 2010 power (SVC) and reducing power output of the NDS.

\section{Modeling of Distribution Systems}

\subsection{Load modeling for primary feeder}

At first, one section is defined to represent a load modeling of the primary feeder ${ }^{[7]-[8]}$. Properly dividing a primary feeder according to certain rules such as changing point of wire size, branch point, location of voltage regulators, etc was performed to determine the section. Then, the total load amount in a feeder is estimated from the sum of both load amount of low voltage customers (kwh) and high voltage customers (kw) as shown in Fig. 1.

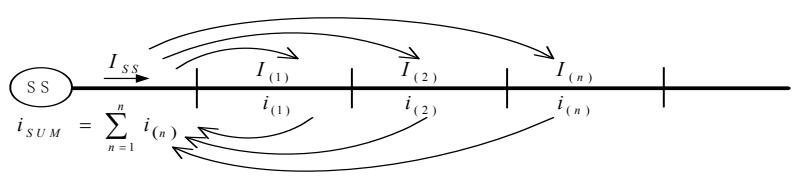

Fig. 1. Load modeling of primary feeders.

Real current value of a section can be calculated using

$$
I_{(n)}=i_{(n)} \times \frac{I_{S S}}{i_{S U M}}
$$

where, $I_{(n)}$ and $i_{(n)}$ are real and estimated currents of $n$ sec- 


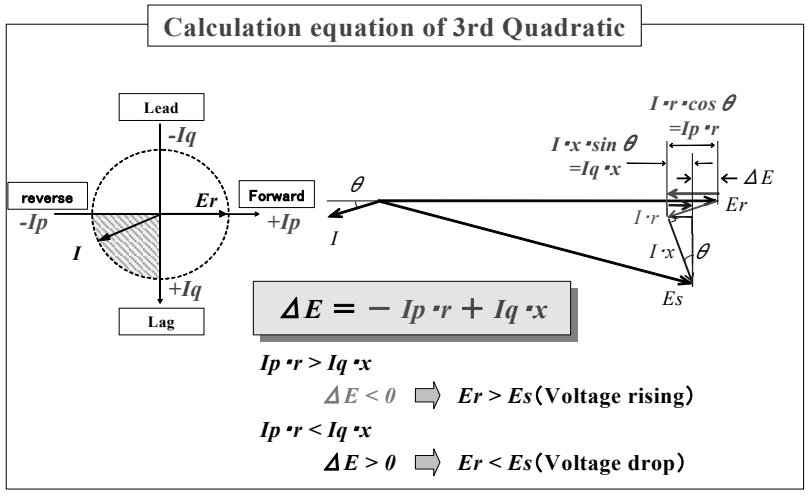

Fig. 2. Voltage profile calculation of 3rd Quadratic.

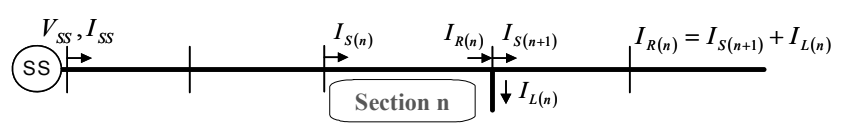

Fig. 3. Inflow and outflow current in n section.

tion, $\mathrm{I}_{\mathrm{SS}}$ is the measured (real) total current of the primary feeder, and $\mathrm{i}_{\mathrm{SUM}}$ is the estimated total current.

Eq. (1) shows that the real value of each section can be obtained from the relationship between estimation value and measured value.

\subsection{Algorithm for Voltage Profile Calculation}

Typical algorithms could handle the voltage drop of a section by considering the power flow from distribution substations(sources) only as one direction. However, the voltage rise can be also considered in the case where the reverse power flow of NDS is present. Thus, this paper proposes an idea that the load current (I) is divided into 2 separate parts of real part $\left(\mathrm{I}_{\mathrm{p}}\right)$ and imaginary part $\left(\mathrm{I}_{\mathrm{q}}\right)$ in order to properly consider the load flow direction and power factor (imaginary power, Q) of NDS. As shown in Fig. 2, the forward power flow from sources to loads and the lead power factor do not exist in the 3rd quadrant, and the reverse power flow and lag power factor must be considered at the voltage profile calculation. Thus, the voltage rise according to the reverse power flow occurs in the quadrant. In the same way, the voltage profile equations in 1 st, $2^{\text {nd }}$, and 4 th quadrants can be obtained.

The typical equation for voltage drop is expressed by $\triangle \mathrm{V}=\mathrm{Z}$ (impedance) $\times \mathrm{I}$ (current). The new equation can be expanded by considering the concepts of 4 quadratics and real and reactive currents as:

$$
\Delta V_{(n)}=k \cdot\left\{\frac{I_{S p(n)}+I_{R p(n)}}{2} \cdot r_{(n)}+\frac{I_{S q(n)}+I_{R q(n)}}{2} \cdot x_{(n)}\right\}
$$

where, $I_{\mathrm{sp}(\mathrm{n})}$ and $\mathrm{I}_{\mathrm{sq}(\mathrm{n})}$ are real and reactive inflow current in nth section as shown in Fig.3, $\mathrm{I}_{\mathrm{Rp}(\mathrm{n})}$ and $\mathrm{I}_{\mathrm{Rq}(\mathrm{n})}$ are real and reactive outflow current in $n$th section, $\mathrm{r}_{(\mathrm{n})}$ and $\mathrm{x}_{(\mathrm{n})}$ are resister and reactance in $n$th section, $\triangle V_{(n)}$ is voltage profile

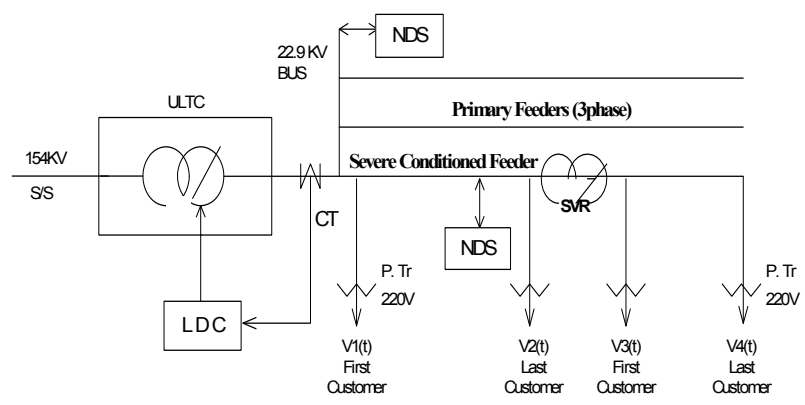

Fig. 4. Concepts for the voltage regulation at distribution systems

in nth section.

\section{Optimal Operation Algorithms of Voltage Regulators}

The Line Drop Compensation (LDC) method [8]-[11] of voltage regulators in Fig. 4 is currently used in many power utilities in maintaining customer voltages within the allowable limits $(220 \pm 6 \%)$. The method is based on the concept of an imaginary standard feeder to represent total feeder characteristics. The sending voltages at voltage regulators located at distribution substations (ULTC) and primary feeders (SVR) determines the LDC setting values. In this study, the ideal sending voltages expressed by the optimal compensation rates were first determined and then optimal LDC setting values by the statistical analysis according to the relationship between ideal optimal sending voltages and total load currents were obtained.

\subsection{Optimal Compensation Rates}

The sending voltages of the substations are generally controlled by ULTC (Under-load Tap Changer). The determination of LDC setting values is very complicated due to the randomness of the load variations and the operation of NDS. This study assumes that other feeders of the main transformer are with reasonable voltage distributions and if all customers throughout the worst conditioned feeder with the biggest voltage drop and a severe voltage fluctuation are maintained within the allowable voltage limits. Therefore, the deciding problem in optimal sending voltage is to obtain the compensation rates of ULTC, and can be formulated as:

$$
\begin{aligned}
\operatorname{MinJ}(t) & =\left\{V_{1, \text { max }}(t)-V_{1}(t) \times X_{m t r} / R_{m t r}\right\}^{2} \\
& +\left\{V_{1}(t) \times X_{m t r} / R_{m t r}-V_{1, \text { min }}(t)\right\}^{2}
\end{aligned}
$$

Subj. to, $\quad V_{1, \max }(t)=V_{\max }$

$$
V_{1, \min }(t)=V_{\min } \times V_{1}(t) / V_{2}(t)
$$

where, $\mathrm{V}_{\max }$ and $\mathrm{V}_{\min }$ are the upper and lower limits of al- 


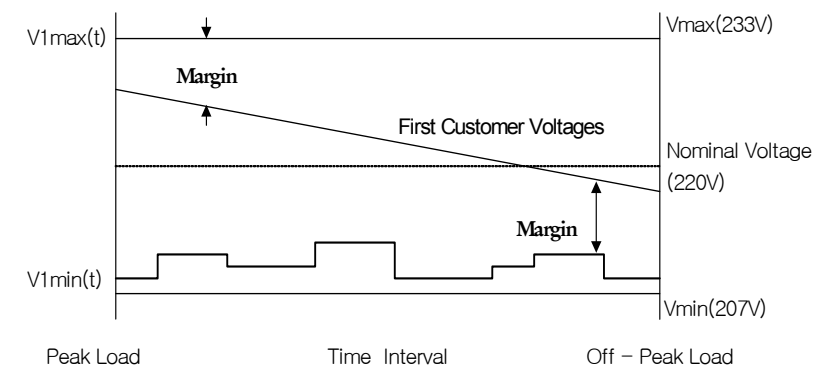

Fig. 5. Concept for the Optimal Voltage Regulation.

lowable voltage, $\mathrm{V}_{1}(\mathrm{t})$ and $\mathrm{V}_{2}(\mathrm{t})$ are the first (highest) and last (lowest) customer voltages in the covering area of ULTC, $\mathrm{V}_{1, \max }(\mathrm{t})$ and $\mathrm{V}_{1 \text {,min }}(\mathrm{t})$ are the conversion values of upper and lower voltage limits, $\mathrm{R}_{\mathrm{mtr}}$ and $\mathrm{X}_{\mathrm{mtr}}$ are the existing and optimal voltage compensation rates of ULTC.

This objective function shows that all customer voltages at each time interval have a maximum margin from the upper and lower limits to keep those voltages closer to the nominal voltage as shown in Fig. 5. Furthermore, the squared value of differences between the upper and lower voltage limits and the first customer voltages must be minimized. The voltage of last customer is converted into the voltage of first customer to avoid computation errors and simplify the problem. This is based on the fact that the relationship between the first and last customer voltages is proportional to voltage drop of primary feeder. UThe allowable limits of customer voltages can be reformed as Eq. (4) and Eq. (5). By minimizing this objective function, the desired voltage distributions of all customers can be obtained. The condition for the minimization of Eq.(3) is $\mathrm{dJ}$ $/ \mathrm{dX}_{\mathrm{mtr}}=0$, and the optimal compensation rate of ULTC, $\mathrm{X}_{\mathrm{mtr}}$, can then be expressed using Eq. (6).

$$
X_{m t r}=R_{m t r} \times\left\{V_{1, \text { max }}(t)-V_{1, \text { min }}(t)\right\}^{2} / 2 V_{1}(t)
$$

The optimal sending voltages are obtained by multiplying the $\mathrm{X}_{\mathrm{mtr}}$ by the rated voltage of ULTC.

\subsection{Optimal LDC Setting Values}

The LDC setting values are composed of load center voltage and equivalent impedance. These are operated at the same values for a long period once they are fixed. The compensated sending voltages regulated by the values are essentially identical to the optimal sending voltages obtained by Eq. (6). The optimal sending voltages have a general relationship with the LDC setting values as shown in Eq. (7).

$$
V_{o p t}(t)=V_{c e}+Z_{e q} \times I_{t o}{ }^{\prime}(t)
$$

where, $V_{o p}(t)$ is the optimal sending voltage obtained by $\mathrm{X}_{\mathrm{mtr}}, \mathrm{V}_{\mathrm{ce}}$ is the load center voltage, $\mathrm{Z}_{\text {eq }}$ is the equivalent impedance, and $I_{t o}{ }^{\prime}(t)$ is the total load current of ULTC considering dispersed sources.

Optimal setting values can be obtained by solving the

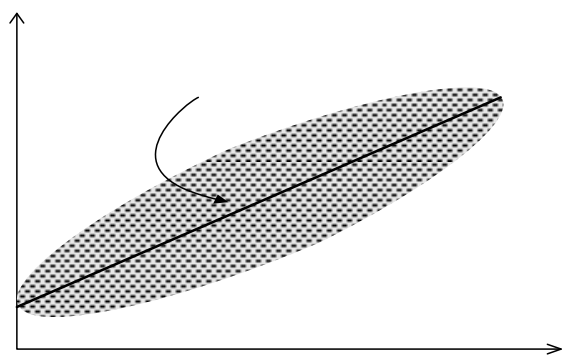

Fig. 6. Distribution characteristics of optimal sending voltage

equation for $\mathrm{V}_{\mathrm{ce}}$ and $\mathrm{Z}_{\mathrm{eq}}$. However, it is difficult to solve this because the relationship between the optimal sending voltages and the total load currents has wide distribution characteristics and a non-linear equation as shown in Fig. 6. The solution problem of optimal LDC setting values is equivalent to determining coefficients of the first order equation of Eq. (7). In order to solve the non-linear equation, the Least Square method is now adapted as

$$
\text { Min, } q=\sum_{t=1}^{T}\left\{V_{o p t}(t)-\left(V_{c e}+Z_{e q} \times I_{t o}{ }^{\prime}(t)\right)\right\}^{2}
$$

By minimizing $\mathrm{q}\left(\partial \mathrm{q} / \partial \mathrm{Z}_{\mathrm{eq}}+\partial_{\mathrm{q}} / \partial \mathrm{V}_{\mathrm{ce}}=0\right)$, optimal LDC setting values $\left(\mathrm{V}_{\text {ce }}\right.$ and $\left.\mathrm{Z}_{\mathrm{eq}}\right)$ can be obtained as

$$
\begin{gathered}
Z_{e q}=\left\{\sum_{t=1}^{T} I_{t o}{ }^{\prime}(t) \times \sum_{t=1}^{T} V_{o p}(t)-T \times \sum_{t=1}^{T} I_{t o}{ }^{\prime}(t) \times V_{o p}(t)\right\} / \\
\left\{\left\{\sum_{t=1}^{T} I_{t o}{ }^{\prime}(t)\right)^{2}-T \times \sum_{t=1}^{T}\left(I_{t o}{ }^{\prime}(t)\right)^{2}\right\} \\
\left.V_{c e}=\sum_{t=1}^{T} V_{o p}(t)-Z_{e q} \times \sum_{t=1}^{T}\left(I_{t o}{ }^{\prime}(t)\right)\right\}
\end{gathered}
$$

\subsection{Optimal Coordination of Multiple Voltage Regu- lators}

Step voltage regulators (SVR) are generally located at the primary feeders to compensate voltage fluctuation in the long distance feeders. In order to maintain the customer voltages throughout the feeder within the allowable limits, the optimal coordination strategy between ULTC and SVR is required. The decision problem for optimal sending voltages of ULTC and SVR can be formulated by the same algorithm as mentioned earlier.

The relationship of customer voltages in the covering areas of ULTC and SVR can be expressed by the voltage drop of primary feeder as:

$$
\begin{aligned}
& \mathrm{V}_{1}(\mathrm{t}) \times \mathrm{P}_{\text {tap } 1}-\mathrm{V}_{\text {drop }}(\mathrm{t})=\mathrm{V}_{3}(\mathrm{t}) \times \mathrm{P}_{\text {tap } 3} \times \mathrm{V}_{\text {tap }} /\left(\mathrm{V}_{\mathrm{n}} \times \mathrm{R}_{\mathrm{vr}}\right) \\
& \mathrm{V}_{\text {drop }}(\mathrm{t})=\left\{\mathrm{V}_{1}(\mathrm{t}) \times \mathrm{P}_{\text {tap } 1}-\mathrm{V}_{3}(\mathrm{t}) \times \mathrm{P}_{\text {tap } 3} \times \mathrm{V}_{\text {tap }} /\left(\mathrm{V}_{\mathrm{n}} \times \mathrm{R}_{\mathrm{vr}}\right)\right\}
\end{aligned}
$$


where, $\mathrm{V}_{\text {drop }}(\mathrm{t})$ is voltage drop of the primary feeder from ULTC to SVR, $V_{3}(t)$ is first customer voltage in the covering area of SVR, $\mathrm{P}_{\text {tap } 1}$ and $\mathrm{P}_{\text {tap } 3}$ are the tap voltages of pole transformer at ULTC and SVR, $\mathrm{V}_{\mathrm{n}}$, and $\mathrm{V}_{\text {tap }}$ are rated and tap voltage of SVR, and $R_{v r}$ is voltage compensation rate of SVR.

Therefore, $\mathrm{V}_{3}(\mathrm{t})$ of Eq.(11-1) can be expressed as:

$$
\begin{aligned}
\mathrm{V}_{3}(\mathrm{t})=\{ & \left\{\mathrm{V}_{1}(\mathrm{t}) \times \mathrm{P}_{\text {tap } 1}-\mathrm{V}_{\text {drop }}(\mathrm{t})\right\} \times \mathrm{V}_{\mathrm{n}} \times \mathrm{R}_{\mathrm{vr}} / \\
& \left(\mathrm{P}_{\text {tap } 3} \times \mathrm{V}_{\text {tap }}\right)
\end{aligned}
$$

By applying optimal compensation rate to Eq. (12), $\mathrm{V}_{3 \mathrm{X}}(\mathrm{t})$ can be obtained as follows :

$$
\begin{aligned}
\mathrm{V}_{3 \mathrm{X}}(\mathrm{t})= & \left\{\mathrm{V}_{1}(\mathrm{t}) \times \mathrm{P}_{\text {tap } 1} \times X m t r / R m t r-\mathrm{V}_{\text {drop }}(\mathrm{t})\right\} \\
& \times \mathrm{V}_{\mathrm{n}} \times \mathrm{X}_{\mathrm{vr}} / \quad\left(\mathrm{P}_{\text {tap } 3} \times \mathrm{V}_{\text {tap }}\right)
\end{aligned}
$$

By substituting Eq. (11-2) to Eq. (13), the relationship of first customer voltages between ULTC and SVR can be expressed as:

$$
\begin{aligned}
\mathrm{V}_{3 \mathrm{X}}(\mathrm{t})=\left\{\left(\mathrm{V}_{3}(\mathrm{t}) \times\right.\right. & \left.X_{v r} / R_{v r}\right)-\mathrm{V}_{1}(\mathrm{t}) \times \mathrm{P}_{\text {tap }}\left(\mathrm{X}_{\mathrm{mtr}} / \mathrm{R}_{\mathrm{mtr}}-1\right) \\
& \times X v r \times \mathrm{Vn} \times / \mathrm{Vtap}\}
\end{aligned}
$$

Where, $\mathrm{P}_{\text {tap }}$ is the ratio of $\mathrm{P}_{\text {tap } 1}$ and $\mathrm{P}_{\text {tap } 3}$

By substituting the Eq. (3) for Eq. (11)-(14), the decision problem for the optimal compensation rates of multiple voltage regulators can be expanded as follows :

$$
\begin{aligned}
\operatorname{MinJ}(t)= & \left\{V_{1 \max }(t)-V_{1}(t) \times X_{m t r} / R_{m t r}\right\}^{2} \\
+ & \left\{V_{1}(t) \times X_{m t r} / R_{m t r}-V_{1, \min }(t)\right\}^{2} \\
& +\{V 3 \max (t)-V 3(t) \times X v r / R v r+V 1(t) \times X v r \times \\
& (X m t r / R m t r-1) \times P t a p \times V n / V t a p\}^{2}+\{V 3(t) \times \\
& X v r / R v r-V 1(t) \times X v r \times(X m t r / R m t r-1) \times P t a p \\
\times & V n / V t a p-V 3 \min (t)\}^{2}+k\{X m t r-X v r\}^{2}
\end{aligned}
$$

where, $\mathrm{V}_{4}(\mathrm{t})$ is last customer voltage at $\mathrm{SVR}, \mathrm{V}_{3, \max }(\mathrm{t})$ and $\mathrm{V}_{3 \text {,min }}(\mathrm{t})$ are the conversion values of upper and lower voltage limits at SVR, $X_{\mathrm{vr}}$ is the optimal voltage compensation rate of SVR, and $\mathrm{K}$ is weighting factor for coordination level.

The objective function indicates that all customer voltages throughout the feeder are maintained with the reasonable voltage limits according to the proper coordination of ULTC and SVR. The 1st and 2nd terms represent the optimal control of ULTC, the 3rd and 4th terms are the optimal control of SVR. The 5th term is the weighting factor of coordination between ULTC and SVR. The condition for the minimization of the Eq. (14) can be obtained using Eq. (17).

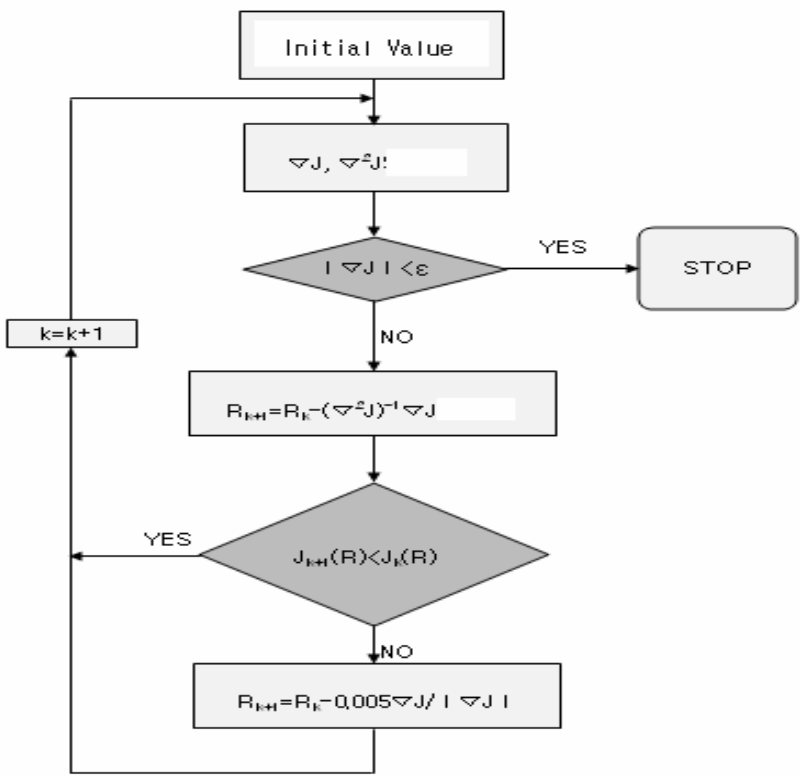

Fig. 7. Flowchart for optimal compensation rates of ULTC and SVR.

$$
\nabla \mathrm{J}=\left[\partial \mathrm{J} / \partial \mathbf{X}_{\mathrm{mtr}}, \partial \partial_{\mathrm{vr}}{ }^{\mathrm{T}}=\right.
$$

$\nabla \mathrm{J}$ is the gradient vector of $\mathrm{Xmtr}$ and $\mathrm{Xvr}$, the elements of matrix are shown in Eq. (18) and (19).

$$
\begin{aligned}
\partial \mathrm{J} / \partial X_{m t r}= & \left\{2 \mathrm{~V}_{1}(\mathrm{t}) / R_{m t r} \times\left(2 V_{1}(t) \times X_{m t r} / R_{m t r}\right.\right. \\
& \left.V_{1, \text { max }}(t)-V_{1, \min }(t)\right\}+\left\{2 V_{1}(t) \times X_{v r} \times V_{n} /\right. \\
& \left(R_{m t r} \times V_{t a p}\right) \times\left(2 V_{1}(t) \times\left(X_{m t r} / R_{m t r}-1.0\right)\right. \\
& \times\left(X_{v r} \times V_{n} / V_{t a p}+2 V_{3}(t) \times X_{v r} / R_{v r}-V_{3, \max }(t)\right. \\
& \left.-V_{3, \min }(t)\right\}+\left\{2 K\left(X_{m t r}-X_{v r}\right)\right\} \\
\partial \mathrm{J} / \partial X_{v r}= & \left\{2 \left(\mathrm{V}_{3}(\mathrm{t}) / R_{v r}+V_{1}(t) \times\left(X_{m t r} / R_{m t r}-1\right)\right.\right. \\
& \times\left(V_{n} / V_{t a p}\right) \times\left(2 X_{v r} \times V_{1}(t) \times\left(V_{n} / V_{t a p}\right) \times\right. \\
& \left(X_{m t r} / R_{m t r}-1.0\right)-V_{3, \text { max }}(t)-V_{3, \text { min }}(t)+ \\
& \left.2 V_{3}(t) \times X_{v r} / R_{v r}\right\}+\left\{2 K\left(X_{v r}-X_{m t r}\right)\right\}
\end{aligned}
$$

As the objective function of Eq. (16) is a nonlinear equation, the quasi-Newton method, which has excellent convergence characteristics, is adopted in this study. The iteration algorithm can be expressed as shown in Eq. (20).

$$
\left[\begin{array}{c}
X_{m t r} \\
X_{v r}
\end{array}\right]^{(k+1)}=\left[\begin{array}{c}
X_{m t r} \\
X_{v r}
\end{array}\right]^{(k)}-\left(B^{(k)}\right)^{-1} \cdot(\nabla J)
$$

where $\mathrm{B}^{(\mathrm{k})}$ is the Hessian vector, which is the approximate value of $\nabla \mathrm{J}^{2}$. Here, the optimal compensation rates of ULTC and SVR are obtained as shown in the flowchart in Fig.7. The error correction at each step is renewed by BGFS equation [9]-[12]. 


\section{Evaluation Algorithm for Voltage Management}

In the typical algorithms for voltage management in the case where the NDS is interconnected with distribution systems, the final decision about its feasibility dependas on the individual ability of a person in charge and the quality of data acquired for the simulations because the typical method evaluates the feasibility of NDS based on the specific system using the different allowable limits. To avoid these problems, the fair and objective algorithm for evaluating the interconnection of the NDS is proposed in this paper. Thus, the evaluating criteria are calculated based on the standard system and the new interconnection of the NDS is evaluated by consistent procedures. The proposed evaluation algorithm is categorized into one for the normal operation and the other for the emergency operation

\subsection{Evaluation Algorithm for Normal Conditions}

A reverse power flow of the NDS may cause the voltage fluctuation at primary feeder, and may encourage voltage variations of customers at secondary feeder. The voltage management at the normal operation requires the conditions that the customer voltages should be kept within the allowable limits $(220 \mathrm{~V} \pm 6 \% ; 207 \mathrm{~V}-233 \mathrm{~V})$, even when voltage variations by the NDS are present. The dotted lines in Fig. 8 represent the new allowable voltage limits at the normal operation, which are obtained by converting the allowable limits into the secondary feeder voltage at secondary side of the pole transformer. The new lower limit of $221 \mathrm{~V}$ is calculated by summing lower limit $(207 \mathrm{~V})$ and the recommended margin $(7 \% ; 14 \mathrm{~V})$ by power utilities. These are the limit of total voltage drop at the secondary side including the voltage drops of pole transformer, secondary feeder, and lead wire. The new value means that the lowest voltage in the secondary customers does not violate the lower limit, only if the voltage at the secondary side is kept above $221 \mathrm{~V}$. The new upper limit of $236 \mathrm{~V}$ is calculated by summing the upper limit $(233 \mathrm{~V})$ and the recommended value $(1.5 \%, 3 \mathrm{~V})$ or the summation of voltage drop of pole transformer and the lead wire. This also means that the highest voltage in the secondary customers does not violate the upper limit, only if the voltage at secondary side is kept below 236V. Based on the voltage limits for the normal operation as shown in Fig.8, the evaluation criteria for interconnecting the NDS can be obtained as following steps.

$<$ Step 1> Assume the new allowable limit of the secondary feeder from the dotted line.

$<$ Step $2>$ Obtain the voltage being charged in the voltage regulators according to the optimal control algorithms in Chapter III, and transform it to the voltage at secondary feeder.

$<$ Step $3>$ Calculate the voltage margin from new allowable limit.

$<$ Step $4>$ Obtain the voltage criteria by converting the remaining voltage into the voltage of primary feeder.

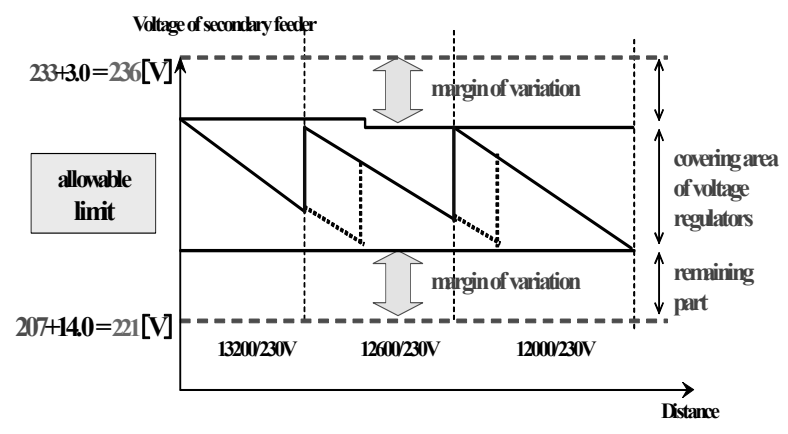

Fig. 8. Voltage criteria for normal operations.

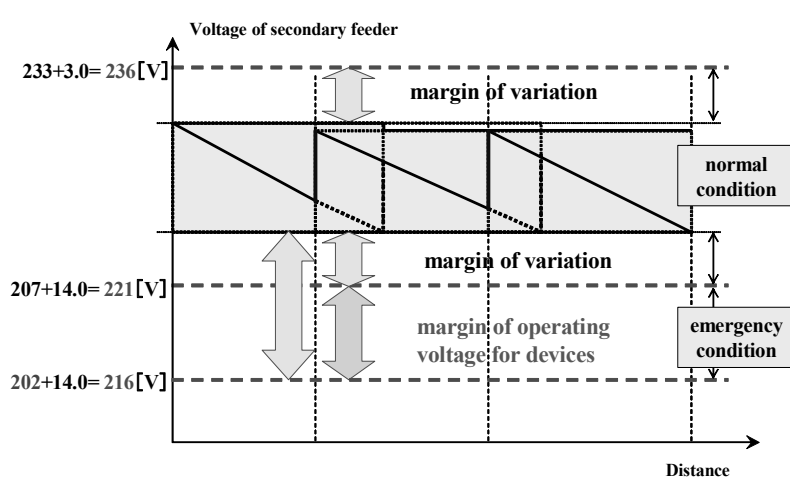

Fig. 9. Voltage criteria for emergency operations.

The criteria value shows that voltages of all customers in the same feeder can be maintained within the allowable limits, if the voltage fluctuation of the primary feeder by the normal operation of dispersed sources is maintained within the value. So, this value can be used as the criteria for deciding whether the dispersed source can be interconnected or not.

\subsection{Evaluation Algorithm for Emergency Conditions}

The short and large voltage variations at the primary feeders may occur at emergency operations such as starting and failure of the NDS. The voltage management at the emergency means that the customer voltages should be kept within the operating voltage limit of electrical devices for a short period (generally less than 2 seconds). Fig. 9 shows new allowable voltage limit at the emergency conditions. The minimum voltage to operate devices is considered as $8 \%$ of nominal voltage, which is recommended by makers of electrical devices. This is based on the idea that electric devices of all customers are only operated during the emergency period.

Based on the voltage limits for the emergency operation shown in Fig.9, the evaluation criteria for interconnecting the dispersed source can be calculated using following steps:

$<$ Step $1>-<$ Step $4>$ same procedure in normal operation. $<$ Step 5>assume the minimum operating voltage for 
electrical devices.

$<$ Step 6>calculate voltage margin at the secondary feeder.

$<$ Step $7>$ convert the voltage margin into voltage at the primary feeder.

$<$ Step $8>$ obtain voltage criteria for emergency conditions by summing value of $<$ step $4>$ and $<$ step $7>$.

This voltage criteria value represents the allowable voltage limits at the primary feeder in the emergency conditions. If the voltage variation at the primary feeder according to dispersed sources is maintained within the value, all customer voltages in the same feeder can be also kept within the allowable limits even in emergency conditions. Thus, this value can be used as the criteria for deciding if the dispersed sources can be interconnected.

\section{Simulations and Analysis}

\subsection{Optimal Voltage Control of Voltage Regulators}

\section{(1) Performance index(PI)}

The criteria of customer voltage distributions can be evaluated by the degree of how close customer voltages are maintained to the nominal voltage. Therefore, a performance index can be defined as a form of the squared differences between the nominal voltage and customer voltages of all nodes as follows:

$$
P_{I}(t)=\sum_{t=1}^{T} \sum_{k=1}^{K}\left\{V_{1}(t, k)-V_{s t d}\right\}^{2}+\left\{V_{s t d}-V_{2}(t, k)\right\}^{2}
$$

where, $\mathrm{P}_{\mathrm{I}}(\mathrm{t})$ is a performance index of time interval $\mathrm{t}, \mathrm{K}$ is the total number of nodes, $V_{1}(t, k)$ and $V_{2}(t, k)$ are the first and last customer voltage of each node, $\mathrm{V}_{\text {std }}$ is the nominal voltage $(220 \mathrm{~V})$, and $\mathrm{T}$ is total time interval.

Reduce the tap operation numbers of voltage regulators is desirable because the tap operation numbers affects the average span of the voltage regulators. This study proposes the counting index to evaluate the algorithm. The tap position $\left(\mathrm{T}_{\mathrm{p}}\right)$ of voltage regulators can be expressed as follows:

$$
T_{p}=T_{s}+\frac{\left(V_{\text {send }}-V_{n}\right)}{\left(T_{\mathrm{int}} \times V_{n}\right)}
$$

where, $\mathrm{V}_{\text {send }}$ is sending voltage of voltage regulators, $\mathrm{V}_{\mathrm{n}}$ is nominal voltage $(22,900 \mathrm{~V}), \mathrm{T}_{\mathrm{s}}$ is position of reference tap, and $\mathrm{T}_{\text {int }}$ is the tap interval of voltage regulators.

\section{(2) Control modes of voltage regulators}

(1) Mode 1 (LDC + Fixed (SVR) Method): ULTC adapts the LDC method and SVR adapts the fixed sending voltage of $22,900 \mathrm{~V}$.

(2) Mode 2 (LDC + Programmed (SVR) Method): ULTC adapts the LDC method and SVR adapts the

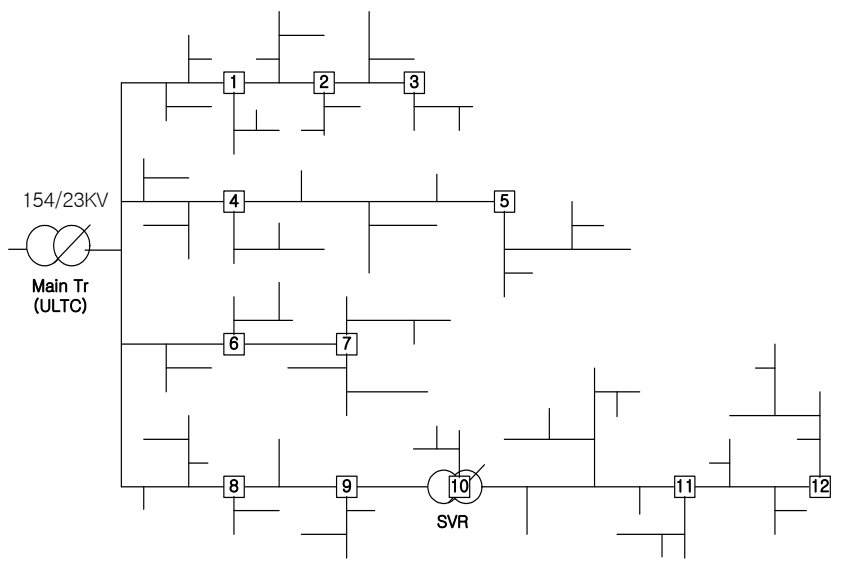

Fig. 10. Simplified distribution systems.

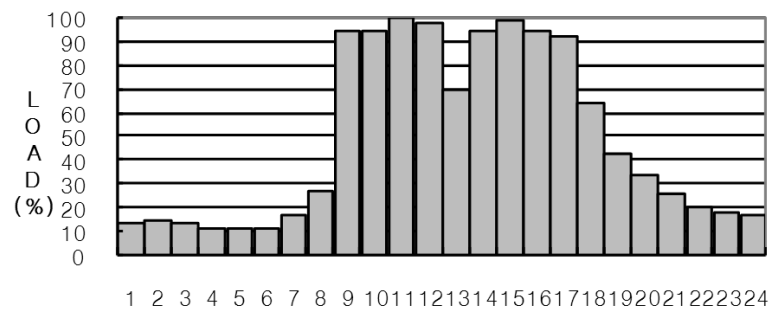

Fig. 11. Daily load curve of main transformer.

\begin{tabular}{|c|c|c|c|c|c|c|c|c|c|}
\hline \multirow{2}{*}{$\begin{array}{c}\text { Feeder } \\
\text { Num- } \\
\text { ber }\end{array}$} & \multirow{2}{*}{$\begin{array}{l}\text { Section } \\
\text { Number }\end{array}$} & \multicolumn{2}{|c|}{$\begin{array}{c}\text { Node } \\
\text { Number }\end{array}$} & \multicolumn{2}{|c|}{ Impedance } & \multirow{2}{*}{$\begin{array}{c}\text { Length } \\
(\mathrm{km})\end{array}$} & \multirow{2}{*}{$\begin{array}{c}\text { Pole } \mathrm{Tr} \\
\text { Tap }\end{array}$} & \multirow{2}{*}{$\begin{array}{c}\text { Load } \\
(\%)\end{array}$} & \multirow[t]{2}{*}{$\begin{array}{l}\text { NDS } \\
(\mathrm{KW})\end{array}$} \\
\hline & & From & To & $\begin{array}{c}\mathrm{R} \\
(\Omega / \mathrm{km})\end{array}$ & $\begin{array}{c}\mathrm{X} \\
(\Omega / \mathrm{km})\end{array}$ & & & & \\
\hline \multirow{3}{*}{1} & 1 & 0 & 1 & 0.182 & 0.391 & 2.0 & $22900 / 230$ & 5 & 0 \\
\hline & 2 & 1 & 2 & 0.182 & 0.391 & 2.0 & $22900 / 230$ & 10 & 0 \\
\hline & 3 & 2 & 3 & 0.182 & 0.391 & 5.0 & $22900 / 230$ & 10 & 0 \\
\hline \multirow{2}{*}{2} & 4 & 0 & 4 & 0.182 & 0.391 & 5.0 & $22900 / 230$ & 10 & 0 \\
\hline & 5 & 4 & 5 & 0.304 & 0.440 & 10.0 & $21800 / 230$ & 15 & 0 \\
\hline \multirow{2}{*}{3} & 6 & 0 & 6 & 0.182 & 0.391 & 4.0 & $22900 / 230$ & 15 & 0 \\
\hline & 7 & 6 & 7 & 0.182 & 0.391 & 4.0 & $22900 / 230$ & 10 & 750 \\
\hline \multirow{5}{*}{4} & 8 & 0 & 8 & 0.182 & 0.391 & 3.0 & $22900 / 230$ & 5 & 750 \\
\hline & 9 & 8 & 9 & 0.182 & 0.391 & 5.0 & $22900 / 230$ & 5 & 750 \\
\hline & 10 & 9 & 10 & 0.182 & 0.391 & 5.0 & $22900 / 230$ & 5 & 0 \\
\hline & 11 & 10 & 11 & 0.304 & 0.440 & 10.0 & $21800 / 230$ & 5 & 0 \\
\hline & 12 & 11 & 12 & 0.304 & 0.440 & 5.0 & $21800 / 230$ & 5 & 0 \\
\hline
\end{tabular}

Table 1. Section data for primary feeders

programmed method having 3 steps in sending voltages.

(3) Mode 3 (LDC + LDC (SVR) Method): ULTC and SVR adapt the LDC method in independent manner.

(4) Mode 4 (Proposed Method): ULTC and SVR adapt the LDC method in coordination manner.

\section{(3) Modeling parameters}

Fig. 10 and Table 1 show a typical distribution system reduced from the real system and section data for primary feeders, respectively. The load patterns as shown in Fig. 11 are assumed, which represent a ratio of the hourly load to the peak load of $45 \mathrm{MW}$. The voltage drops of the pole transformer, secondary feeder, and lead wire at the peak 


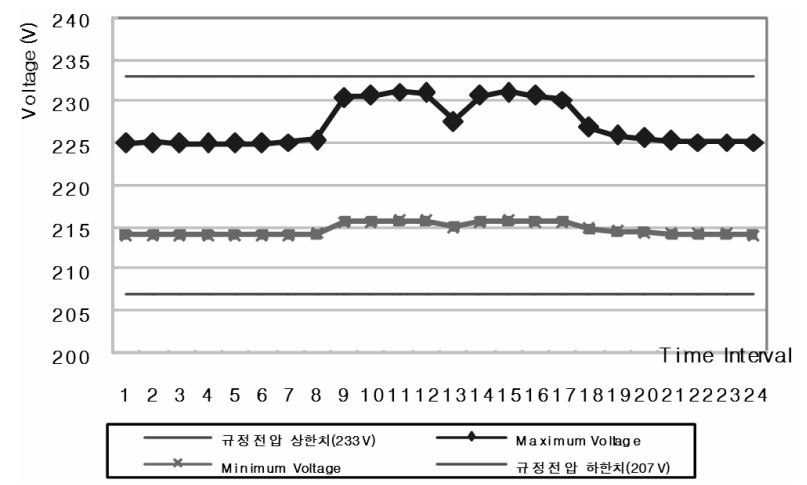

(a) Customer voltage distribution of Mode 3

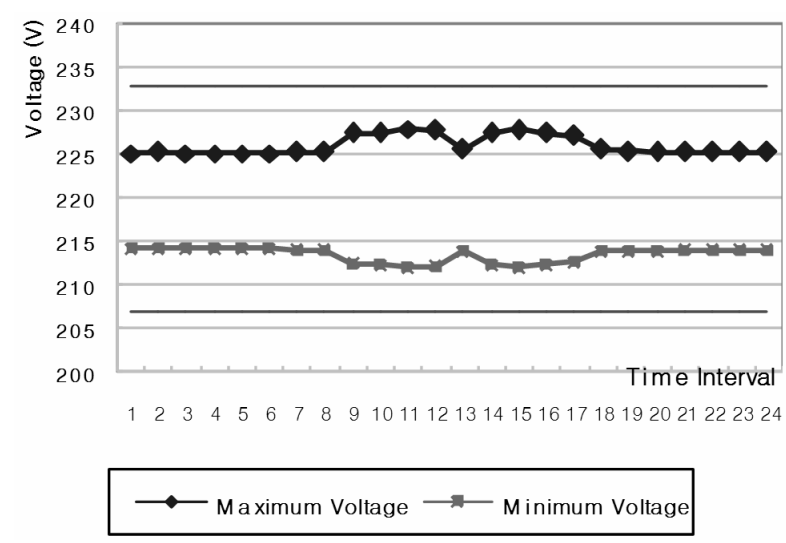

(b) Customer voltage distribution of Mode 4

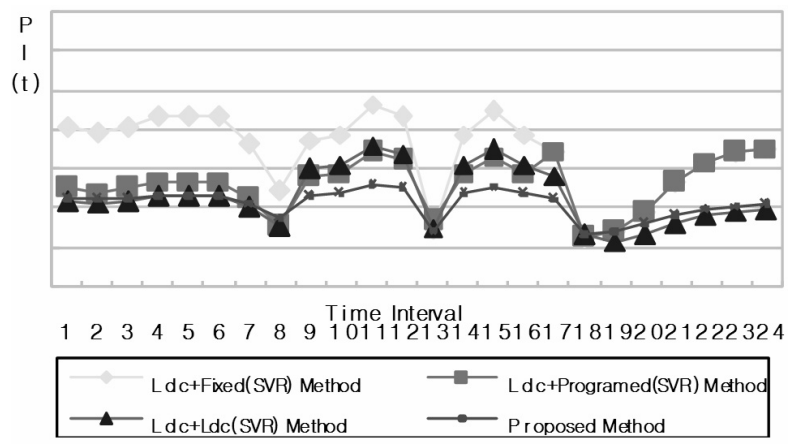

(c) Performance index of all modes

Fig. 12. Customer voltage characteristic and PI.

load are 4.0, 8.0 and 4.0V, respectively. The standard tap changing points of pole transformers are considered as 5\% voltage drop on the basis of $22.9 \mathrm{kV}$. The location of SVR is assumed as the 10 node and new dispersed sources are introduced at the 7, 8, 9 nodes and their total amount is assumed as $10 \%(4,500 \mathrm{~kW})$ of peak load.

\section{(4) Simulation results and analyses}

(a) Before NDS is interconnected

Fig. 12(a) and (b) show the characteristics of voltage distributions of first and last customers performed by the Mode 3 and Mode 4, respectively. Fig. 12(c) shows PI val-

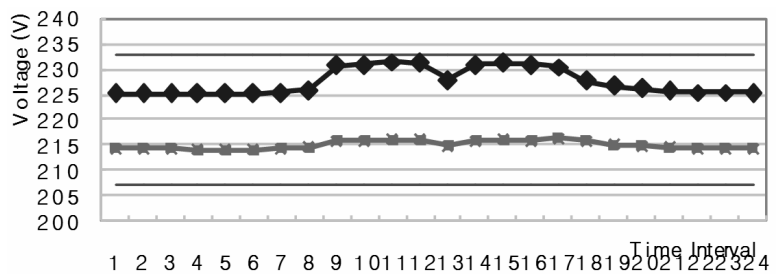

(a) Customer voltage distribution of Mode 3

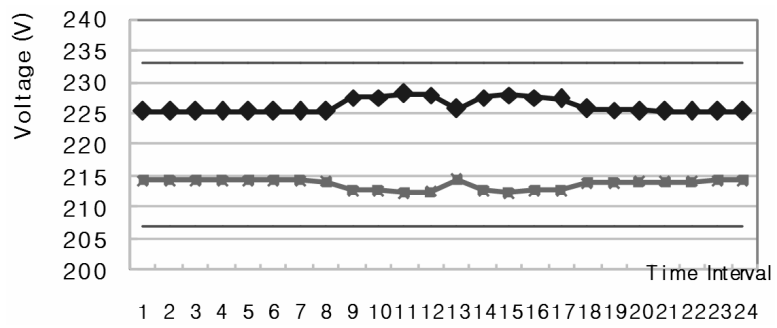

(b) Customer voltage distribution of Mode 4

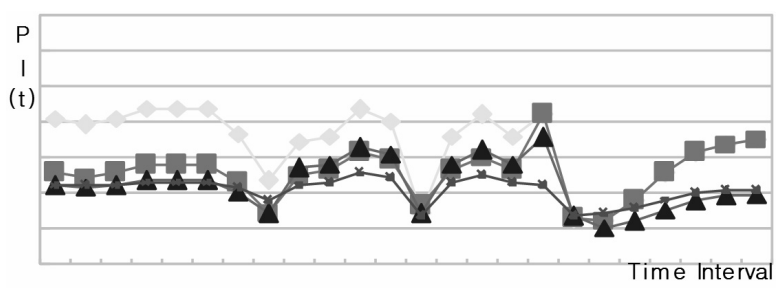

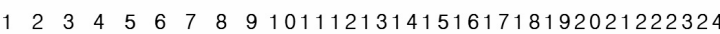

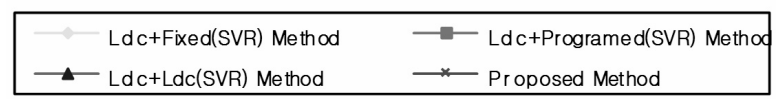

(c) Performance index of all modes

Fig. 13. Customer voltage characteristic and PI.

ues using the all methods. When the NDS is not operated, the proposed method (Mode 4) is to be kept closer to the nominal voltage and to be maintained with more reasonable voltage distribution than other methods.

\section{(b) After NDS is interconnected}

Fig. 13(a) and (b) show the characteristics of voltage distributions of first and last customers performed using Mode 3 and Mode 4, respectively, and Fig. 13(c) is PI values of the all methods where the NDS is introduced at the 7 , 8,9 nodes and the total amount of the NDS is assumed as $10 \%(4,500 \mathrm{~kW})$ of peak load. The proposed method is more effective and recommendable than any other method, like when dispersed sources are not operated. The 3 types of operation modes of the NDS are considered in this paper. The first case (A) is the one where the NDS is not operated, the second case (B) is the NDS without storage function (battery), which only discharge the power for the peak time interval (9-16 time intervals), and the third mode (C) is the NDS with storage function, which discharge for the peak time interval and charge for the off-peak time interval (0-8 time intervals). Table 2 performed by all modes shows that the customer voltage distributions by the proposed method (Mode 4) is maintained with more suitable voltages than 
Table 2. Comparison of PI by all modes

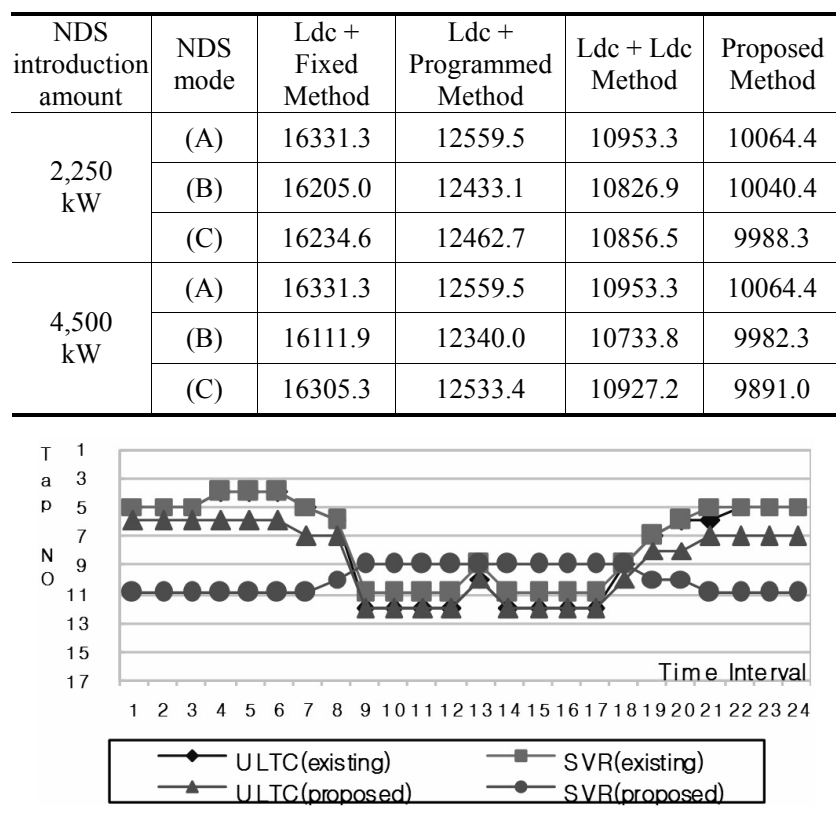

Fig. 14. Tap position of voltage regulators at each method.

other methods.

In addition, the total number of tap operation in Fig. 14 can be remarkably reduced by the proposed method. The method has the capability to feedback customer voltage conditions to the voltage regulators and the proper coordination function between ULTC and SVR.

\subsection{Evaluation Algorithm for Voltage Variations}

\section{(1) Calculation of criteria values}

The criteria value for the normal operation is obtained as:

$<$ Step $1>236 \mathrm{~V}-221 \mathrm{~V}=15 \mathrm{~V}$

$<$ Step $2>600 \mathrm{~V} \times(230 \mathrm{~V} / 12,600 \mathrm{~V})=10.96 \mathrm{~V}$

$<$ Step $3>(15 \mathrm{~V}-10.96 \mathrm{~V}) / 2=2.02 \mathrm{~V}$

$<$ Step $4>2.02 \mathrm{~V} \times(12,600 \mathrm{~V} / 230 \mathrm{~V})=111 \mathrm{~V}$

The value of $600 \mathrm{~V}$ in $<$ Step $2>$ is obtained by considering optimal covering voltage of voltage regulators is about $5 \%$ of the standard voltage $(13,200)$. The single phased value of $111 \mathrm{~V}$ means the allowable limit of voltage variations at primary feeder in the normal conditions. So, if the voltage can be maintained within the value even after the NDS is operated, the all customer voltages at the same feeder can be also maintained within the allowable limits. Therefore, this value can be the criteria for deciding whether the NDS can be interconnected or not.

On the other hand, the criteria value for the emergency condition can be obtained as:

\footnotetext{
$<$ Step $5>220 \mathrm{~V} \times 8 \% \approx 202 \mathrm{~V}$

$<$ Step $6>207 \mathrm{~V}-202 \mathrm{~V}=5 \mathrm{~V}$

$<$ Step $7>5 \mathrm{~V} \times(12,600 / 230)=274 \mathrm{~V}$

$<$ Step $8>111 \mathrm{~V}+274 \mathrm{~V}=385 \mathrm{~V}$
}

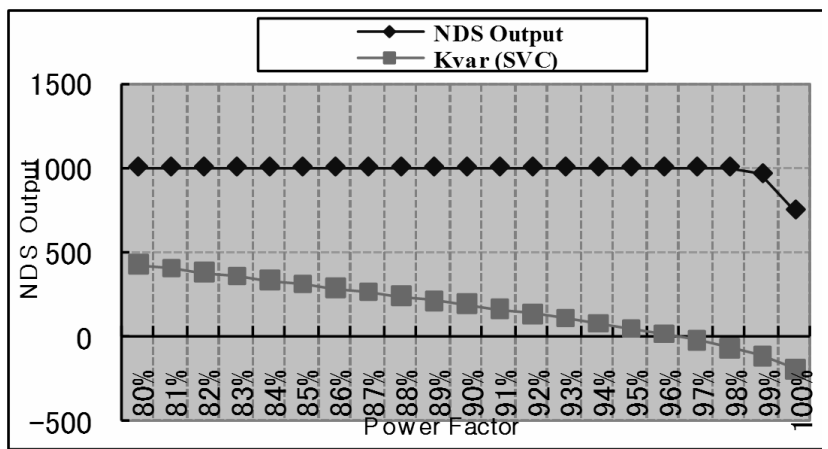

Fig. 15. Evaluation results in the normal conditions.

Table 3. Evaluation results of technical guideline

\begin{tabular}{|c|c|c|c|}
\hline Items & Case I & Case II & Guideline \\
\hline $\begin{array}{l}\text { Power Factor } \\
\text { (Peverse Power) }\end{array}$ & $\begin{array}{c}\text { Good } \\
-500 \mathrm{~kW}, \text { okVar, } \\
100 \%)\end{array}$ & $\begin{array}{c}\text { Bad } \\
(-100 \mathrm{~kW}, 497 \mathrm{kVar}, \\
20 \%)\end{array}$ & Over, $90 \%$ \\
\hline $\begin{array}{c}\text { Normal Voltage } \\
\text { Profile } \\
\end{array}$ & $\begin{array}{c}\text { Good } \\
(-78 \mathrm{~V}) \\
\end{array}$ & $\begin{array}{c}\text { Bad } \\
(120 \mathrm{~V})\end{array}$ & Under $111 \mathrm{~V}$ \\
\hline $\begin{array}{c}\text { Abnormal Voltage } \\
\text { Profile }\end{array}$ & $\begin{array}{c}\text { Bad } \\
(534 \mathrm{~V})\end{array}$ & $\begin{array}{l}\text { Good } \\
(309 V)\end{array}$ & Under $385 \mathrm{~V}$ \\
\hline Ficker $(500 \mathrm{~kW})$ & $\begin{array}{l}\text { Good } \\
(0.29)\end{array}$ & $\begin{array}{l}\text { Good } \\
(0.29)\end{array}$ & Under 0.45 \\
\hline $\begin{array}{l}\text { Short Circuit } \\
\text { Capacity }\end{array}$ & $\begin{array}{c}\text { Good } \\
\text { (503MVA) }\end{array}$ & $\begin{array}{c}\text { Good } \\
(503 \mathrm{MNA})\end{array}$ & $\begin{array}{l}\text { Under } \\
100 \mathrm{M} / \mathrm{A}\end{array}$ \\
\hline $\begin{array}{c}\text { Criteria for } \\
\text { Interconnection }\end{array}$ & Impossible & Impossible & \\
\hline
\end{tabular}

The single phased value of $385 \mathrm{~V}$ is the allowable limit of voltage fluctuations at primary feeder for the case that the operating NDS is committed or tripped. So, if the voltage can be maintained within $385 \mathrm{~V}(1.8 \%)$ even after the NDS is introduced, all customer voltages in the same feeder can be also maintained within the allowable limits. Therefore, this value can also be used as the criteria for the emergency operation.

\section{(2) Analysis and evaluations}

The evaluation algorithm is implemented by Excel program of Microsoft Co. using VBA (Visual Basic Application). For the case study, it is assumed that an induction motor type of wind power generator is introduced at the node of 12 in Fig. 10. The capacity of the wind power is $1 \mathrm{MW}$. Fig. 15 shows that the wind power can be introduced even if the amount of reverse power is kept less than $76 \%$ of its output.

However, if its reverse power exceeds $76 \%$ of its output, the voltage variations due to the reverse power exceeds the criteria value in the normal condition $(111 \mathrm{~V})$, so the evaluation system indicates that this connection is not feasible. Fig. 15 shows that optimal capacity of wind power is $760 \mathrm{kw}$ at the power factor of $100 \%$. This also recommends that the output of wind power should be reduced for the secure interconnection or it should be interconnected into 
other locations (nodes).

In addition, Table 5 is the interconnection conditions of the wind power based on the parameter of the wind power capacity, where the wind power is located at the node 12 . The Case I is assumed by $1 \mathrm{MW}$ capacity of the wind power, and The Case II is $0.6 \mathrm{MW}$. Table 5 shows that Case I is not feasible for exceeding the guideline value, but Case II did not show any problems at the interconnection of the wind power. Therefore, the proposed algorithm is a practical tool in evaluating the technical guideline (interconnection connections) of NPS like wind power.

\section{Conclusion}

In this study, the optimal voltage control of multiple voltage regulators and evaluation criteria algorithm for new dispersed sources interconnected in the distribution systems was discussed. By comparing between the proposed methods and other methods, their effectiveness was illustrated and demonstrated as follows.

(1) The customer voltages by the proposed method could be kept closer to nominal voltage and maintained with more suitable conditions than the typical methods.

(2) The total number of tap operation of voltage regulators by the proposed method can be remarkably reduced. The method has the capability to feedback customer voltage conditions to the voltage regulators and proper coordination between ULTC and SVR.

(3) The proposed algorithm can be applied to the distribution systems before the dispersed source is introduced as well as after the dispersed source is introduced. In addition to these, the proposed algorithm can also propose alternatives in solving any problems found in the evaluation.

(4) The proposed values of the algorithm at normal and emergency operations can be used as the criteria for deciding whether the dispersed source can be connected or not.

(5) As the algorithm offers reasonable evaluation and some countermeasures in advance, the planners and manufactures of dispersed sources can prevent several problems related to the interconnection. So, their economical profit can be also expected by avoiding the additional options.

Therefore, the proposed algorithms can play a role in improving the power quality for the customer as well as the efficiency of the work for manufacturers and operators of dispersed sources.

\section{Acknowledgment}

This work was supported by the Power Generation \&
Electricity Delivery of the Korea Institute of Energy Technology Evaluation and Planning (KETEP) grant funded by the Korea government Ministry of Knowledge Economy. (No. 20101020300430)

\section{References}

[1] NREL, "Distributed Power Program DER Pilot Test at the Nevada Test Site", NREL/TP 560-32063, 2002.5

[2] EPRI, "Electricity Technology Roadmap, Meeting the Critical Challenge of the $21^{\text {st }}$ Century", Product No. 10100929, 2003

[3] R. Grunbaum, "SVC Light: A Powerful Means for Dynamic Voltage and Power Quality Control in Industry and Distribution", Power Electronics and Variable Speed Drives, pp. 404-409, 18-19 September 2000, Eighth International Conference Publication No.475@ IEE 2000.

[4] V. Karasik, K. Dixon, C. Weber, B. Batchelder, G. Campbell, and Ribeiro, "SMES for Power Utility Applications: A Review of Technical and Cost Considerations," IEEE Trans. Applied Superconductivity, Vol. 9, No. 2, June 1999.

[5] Lin C. E., Shiao Y. S., Huang C. L. and Sung P. S, "Design Consideration and Economical Evaluation for Battery Energy Storage System", 92 IEEE PES Summer Meeting, SM 431-7 PWRS, Seattle Washington, July 1992.

[6] H. Kirkham \& R. Das, "Effects of Voltage Control in Utility Interactive Dispersed Storage and Generation Systems", IEEE Trans. Power Apparatus and Systems, Vol. PAS-103, No.8, 1984

[7] Vasilije P. Lulcic, "Optimal Operation Policy for Energy Storage”, IEEE Trans. PAS-101, No. 9 (1982)

[8] James J. Burke, "Power Distribution Engineering", Marcel Dekker, Inc. pp. 320-348 (1994).

[9] H. Lee Willis, "Power Distribution Planning Reference Book”, Marcel Dekker, Inc. pp. 185-228 (1997).

[10] D. Rho, H. Kita, K. Nishiya \& J. Hasegawa, "Voltage Regulation Methods Based on an Extended Approach and Neural Networks for Distribution System with DSG systems", Trans IEEJ, Vol. 117B, No. 3, 1997.

[11] Optimal Voltage Regulation Methods in Distribution Systems Interconnected with DSG Systems, IEEJP \& Society, No.345 (1995).

[12] D. Rho, H. Kita, K. Nishiya \& J. Hasegawa, "A Study on the Optimal Voltage Regulation Methods at the Power Distribution Systems Interconnected with DSG Systems", EMPD'95, IEEE Catalogue No. 95TH8130, S26.2 (1995).

[13] D. Rho, E.S. Kim, J.E. Kim and J. Hasegawa, "Basic Studies on the Impacts of Customer Voltages by the Operation of the Flexible Reliable and Intelligent Energy Delivery Systems", Trans. Proceedings of the 
IASTED International Conference, October 27-30, 1997, Orlando, Florida.

[14] D. Rho, M. Kim, "A study on the Optimal Operation of Line Voltage Regulator (SVR) in Distribution Feeders", 2004 IFAC Symposium, Seoul, South Korea, 2004. 9.

[15] M. Kim, D. Rho, J. Kim, K. Kim, "Optimal Operation Method of Multiple Voltage Regulators in Distribution Systems Interconnected with Dispersed Storage and Generation Systems", Trans. KIEE. Vol. 54A. No. 2, 2005. 2.

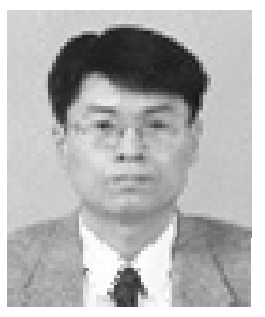

Dae-Seok Rho received B.S. and M.S. degrees in Electrical Engineering from Korea University, Seoul, South Korea in 1985 and 1987, respectively. $\mathrm{He}$ earned a Ph.D. degree in Electrical Engineering from Hokkaido University, Sapporo, Japan in 1997. He has been working as an associate professor at Korea University of Technology and Education since 1999. His research interests include operation of power distribution systems, dispersed storage and generation systems and power quality.

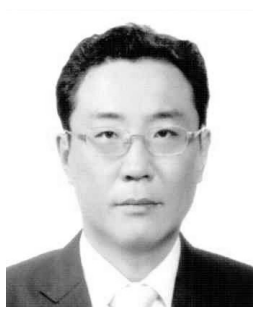

Yong-Peel Wang received the B.S., M.E. and Ph. D degree in Electrical Engineering from Dong-A University, Busan, South Korea, in 1992, 1994, and 1998, respectively. He was a post doctoral fellow from 1999-2001 at Canterbury University, New Zealand and a lecturer from 2001-2008 at Dong-A University. He has been working as a Senior Researcher at Electrical Industry Research Institute of Korea since 2009. His research interests include operation of power distribution systems, HVDC power systems, electromagnetic transient, and power quality.

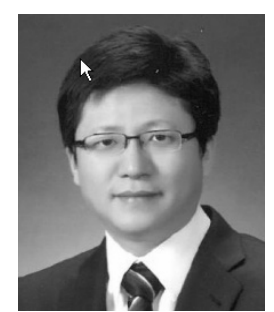

Kyung Soo Kook received his B.S. and M.S. degrees from Korea University, Seoul, South Korea in 1996 and 1998, and Ph.D. from Virginia Tech., USA, in 2007, , all in Electrical Engineering. From 1998 to 2004 he was with Korea Electro-technology Research Institute(KERI) as a researcher and senior researcher. From 2007 to 2010, he was with Electric Power Research Institute(EPRI) as a senior project engineer. In May 2010, he joined Chonbuk National University as a faculty member at the department of electrical engineering. 